\title{
Impact of smoking on mortality and life expectancy in Japanese smokers: a prospective cohort study
}

\author{
() (1) $\Theta$ OPEN ACCESS
}

\author{
R Sakata associate senior scientist ${ }^{1}$, P McGale senior statistician ${ }^{2}$, E J Grant assistant department \\ chief $^{1}$, K Ozasa department chief ${ }^{1}$, R Peto professor ${ }^{2}$, S C Darby professor ${ }^{2}$
}

${ }^{1}$ Department of Epidemiology, Radiation Effects Research Foundation, Hiroshima, Japan; ${ }^{2}$ Clinical Trial Service Unit, University of Oxford, Oxford OX3 7LF, UK

\begin{abstract}
Objective To investigate the impact of smoking on overall mortality and life expectancy in a large Japanese population, including some who smoked throughout adult life.

Design The Life Span Study, a population-based prospective study, initiated in 1950.

Setting Hiroshima and Nagasaki, Japan.

Participants Smoking status for 27311 men and 40662 women was obtained during 1963-92. Mortality from one year after first ascertainment of smoking status until 1 January 2008 has been analysed.
\end{abstract}

Main outcome measures Mortality from all causes in current, former, and never smokers.

Results Smokers born in later decades tended to smoke more cigarettes per day than those born earlier, and to have started smoking at a younger age. Among those born during 1920-45 (median 1933) and who started smoking before age 20 years, men smoked on average 23 cigarettes/day, while women smoked 17 cigarettes/day, and, for those who continued smoking, overall mortality was more than doubled in both sexes (rate ratios versus never smokers: men 2.21 (95\% confidence interval 1.97 to 2.48 ), women 2.61 (1.98 to 3.44)) and life expectancy was reduced by almost a decade ( 8 years for men, 10 years for women). Those who stopped smoking before age 35 avoided almost all of the excess risk among continuing smokers, while those who stopped smoking before age 45 avoided most of it.

Conclusions The lower smoking related hazards reported previously in Japan may have been due to earlier birth cohorts starting to smoke when older and smoking fewer cigarettes per day. In Japan, as elsewhere, those who start smoking in early adult life and continue smoking lose on average about a decade of life. Much of the risk can, however, be avoided by giving up smoking before age 35 , and preferably well before age 35 .

\section{Introduction}

Many studies of the effects of smoking on mortality have been carried out in Japan and these have led to the qualitative conclusion that smoking causes the same diseases in Japan as elsewhere. ${ }^{1}$ Quantitatively, however, several of these studies have suggested that the magnitude of the effect of active smoking on overall mortality is smaller in Japan than in other countries. For example, a recent analysis of data from three large scale cohorts based on general Japanese populations suggested that smoking reduced life expectancy by only about four years in both men and women, ${ }^{2}$ while an analysis of data from another large cohort suggested that smoking reduced life expectancy by four years in men and two years in women. ${ }^{3}$ Such reductions in life expectancy are substantially smaller than the 10 year reduction seen in the British Doctors' Study for male smokers born during 1900-30, ${ }^{4}$ and the nine year reduction in men and eight year reduction in women seen in the Framingham Heart Study in the United States. ${ }^{5}$

In this report we investigate the impact of smoking on overall mortality in the Life Span Study (LSS), a large cohort that is made up partly of atomic bomb survivors and and partly of a sex and age matched sample of other people who were residents of the cities of Hiroshima and Nagasaki in 1950 and born before August 1945 but who were not in the cities at the time of the bombings. Some analyses of the effect of smoking on subsequent mortality from specific diseases ${ }^{67}$ and of the extent to which smoking modifies the risks resulting from radiation exposure ${ }^{89}$ have been carried out, but the overall impact of prolonged smoking on overall mortality and life expectancy in this cohort has not previously been described. Although the primary purpose of the LSS was to investigate the effects of radiation, about half the 120000 cohort members were either away from the cities at the time of the bombings or else sufficiently far away from the hypocentres of the blasts to have received exposure 
comparable to only one or two years of natural background radiation (that is, $<5 \mathrm{mGy}$ ). The remaining half were exposed to whole body radiation at an average dose of $170 \mathrm{mGy}$, and it is estimated that about $3 \%$ of their deaths since 1950 are attributable to radiation. ${ }^{10}$

\section{Methods}

\section{Material}

The 1950 Japanese national census included a supplementary question about location at the time of the atomic bombings (6 August 1945 for Hiroshima and 9 August for Nagasaki). Based on the information obtained, the LSS cohort of 120321 people was established. Smoking information was not obtained for the cohort when it was initiated, but was sought from a large proportion of those surviving in a series of mail surveys and clinic interviews carried out during $1963-92^{11}$ (table $1 \Downarrow$ ). Few people reported smoking products other than cigarettes, and those who did generally reported smoking cigarettes as well. Therefore, smokers of cigarettes and other products have been considered together. Smoking information was ascertained once for 31142 individuals and more than once for 36831 individuals and, where it had changed, an individual's smoking status was updated the following year. Only logically valid changes in smoking status were allowed; subjects were censored when they reported an invalid transition (such as current smoker on one occasion and lifetime non-smoker on a later occasion). The vital status of cohort members has been monitored regularly by means of the Japanese National Family Registration System, and follow-up is complete for $99.8 \%$ of them. When a cohort member dies, the death certificate is obtained. The study was approved by the Radiation Effects Research Foundation institutional review board.

\section{Statistical analysis}

For analyses of death rates, individuals contributed to the person years at risk from the earliest of 1 January 1965 or one year after the first mail survey or clinic interview at which they provided information on smoking status, and they were censored on the earliest of date of death, loss to follow-up, 100th birthday, or 1 January 2008. Deaths and person years at risk were subdivided according to sex; attained age and calendar year (both in five-year groups); smoking status when last asked (never, current, or former); and, for specific analyses, by other factors as well. Analyses were carried out using Poisson regression in Stata version 12.0 and were stratified by age in five-year groups and, where appropriate, also by calendar year in five-year groups. Significance tests were two sided.

Age standardised death rates for never smokers and current smokers by calendar year of birth were obtained via a two stage process. First, Poisson regression models were fitted by maximum likelihood with decade of birth and age (in five-year groups) both as categorical variables. The age standardised death rate in each birth decade was then taken to be the weighted average of the fitted rates at each level of age, with weights equal to the overall proportion of the total person years in each age category. Survival probabilities were estimated using the Kaplan-Meier method. The study did not contain any information on children or young adults. Therefore, survival probabilities from age 35 years were estimated for individuals born during 1920-45, and from age 55 for individuals born before 1920 .

\section{Results \\ Length of follow-up and smoking status}

A total of 27311 men and 40662 women provided information on smoking status at one survey or another, either by mail or at a clinic interview, and the average length of follow-up after first providing information on smoking status was 22.9 years (20.4 for men and 24.6 for women). In the late 1960 s, $74 \%$ of men and $13 \%$ of women reported that they were current smokers, and $13 \%$ of men and $2 \%$ of women reported that they were former smokers (table $2 \Downarrow$ ). In later survey periods, the percentages of current smokers decreased in both sexes and the percentages of former smokers increased. Among current and formers smokers, $25 \%$ of men (5842 individuals) and 5\% of women (357 individuals) reported that they had started smoking before the age of 20 .

\section{Current smokers}

Compared with never smokers, mortality from all causes among current smokers increased progressively with decade of birth: death rate ratios were $1.24,1.39,1.49,1.55,1.82$, and 1.92 respectively for men born before 1890, 1890-99, 1900-09, 1910-19, 1920-29, and 1930-45 (P value for trend $=0.00001$, table $3 \Downarrow)$ and were $1.32,1.38,1.41,1.69,1.82$, and 1.79 respectively for women born in the same periods ( $\mathrm{P}$ value for trend $<0.00001)$. The numbers of cigarettes smoked by current smokers also increased progressively by decade of birth, from 13 per day for men born before 1890 to 24 /day for those born during 1940-45, and from 7/day for women born before 1890 to $13 /$ day for women born during 1940-45 (fig 1 top panel $\Downarrow$ ).

Among all men born before 1920, the overall death rate ratio for current versus never smokers was 1.46 (95\% confidence interval 1.38 to 1.54), while for those born during 1920-45 it was substantially higher, at 1.89 (1.70 to 2.10$)$. For women, the corresponding death rate ratios were 1.51 (1.43 to 1.58$)$ and 1.81 (1.67 to 1.96). The higher death rate ratios in individuals born during 1920-45 compared with individuals born earlier could not be explained by an effect of calendar period, as there was little trend with calendar period in the death rate ratios for current smokers versus never smokers for either men or women (see extra tables 1a and $1 \mathrm{~b}$ in supplementary material on bmj.com). Nor could it be explained by an effect of attained age, as there was little trend in the death rate ratio for current smokers versus never smokers across the three age groups $<60$, $60-69$, and $\geq 70$ years for men born at any time, or for women born before 1920 . Also, the death rate ratios were generally higher for those born during 1920-45 than for those born before 1920 (see extra tables $2 \mathrm{a}$ and $2 \mathrm{~b}$ in supplementary material on bmj.com).

Irrespective of period of birth (<1920 or 1920-1945), and for both sexes, death rate ratios were highest among those who had started smoking before age 20 and lowest among those who did not start smoking until they were at least 30 , and these trends with age at starting smoking were highly significant (table $4 \Downarrow$ ). In both sexes the death rate ratios in individuals born during 1920-45 who started smoking before age 20 were more than two (death rate ratio for men 2.21 (1.97 to 2.48), based on 1121 $v 404$ deaths; death rate ratio for women 2.61 (1.98 to 3.44), based on $51 v 3755$ deaths). If these increases among smokers are largely causal, it suggests that, unless they manage to stop, more than half of these smokers will eventually be killed by smoking.

For both sexes, the mean age at which smokers started to smoke decreased with each successive decade of birth, from 23.4 years 
for men born before 1890 to 19.8 years for those born during 1940-45, and from 36.0 years for women born before 1890 to 24.3 years for women born during 1940-45 (fig $1 \Downarrow$ ). Among men born before 1920 , only $18 \%$ of smokers started smoking before age 20 (extra fig 1 on bmj.com) and the mean number of cigarettes smoked per day was 16 , whereas, among men born during 1920-45, 36\% of smokers started smoking before age 20 and the mean number of cigarettes smoked per day was 23 . Among women born before 1920 , only $6 \%$ of smokers started smoking before age 20 and the mean number of cigarettes smoked per day was 10 , whereas, among women born during $1920-45,8 \%$ of smokers started smoking before age 20 and the mean number of cigarettes smoked per day was 17 . Thus, the increasing death rate ratios for current smokers versus never smokers among those born in later decades (table $3 \Downarrow$ ) can be explained partly by the fact that those born later smoked more cigarettes per day and partly by the fact that a larger proportion of them started to smoke at a younger age.

Among men born during 1920-45 who started to smoke by age $20,72 \%$ survived to age 70 years. In contrast, among men born in the same period who never smoked, $72 \%$ survived to age 78 years (that is, an additional eight years) (fig $2 \Downarrow$ ). For women the difference was just as striking. Among women born during 1920-45 who started to smoke by age 20 , the percentage who survived to age 70 years was $79 \%$. In contrast, among women born in the same period who never smoked, $79 \%$ survived to age 80 years (an additional 10 years). The differences in life expectancy between current and never smokers were greater for smokers who started to smoke before age 20 than for those who did not start to smoke until they were older, and the differences were greater for those born during 1920-45 than for those born before 1920 (extra fig 2c).

\section{Former smokers}

A total of 7120 men and 2432 women reported that they had given up smoking (table $2 \Downarrow$ ). Mortality in former smokers was higher than in never smokers but lower than in those who continued to smoke. There were no significant trends with calendar period in the death rate ratios for former smokers versus never smokers for either men or women (extra tables 1a and $1 \mathrm{~b}$ on bmj.com). However, the earlier that an individual managed to stop smoking the greater the benefit ( $\mathrm{P}$ value for trend $<0.00001$ for people (men and women combined) born before 1920 and $<0.00001$ for people born during 1920-45). (table $5 \Downarrow)$. When the numbers of deaths among former smokers are subdivided by the age when they stopped smoking as well as birth cohort (before or after 1920), they become too small for the analyses to provide statistically reliable estimates. For example, for people (men or women) who were born during 1920-45 and stopped at ages 35-44 years the death rate ratio compared with never smokers was 1.22 (1.06 to 1.40) based on only 246 deaths in former smokers. The confidence interval is wide but, nevertheless, its upper end guarantees substantial avoidance of risk in comparison with those who continued to smoke. Similarly, if we combine men and women born before 1920 with those born during 1920-45 who started smoking at any age and stopped before age 35 , we have only 324 deaths in former smokers (as against 317 expected at the death rates of never smokers: death rate ratio 1.02 (0.91 to 1.13)). Again the upper end of the confidence interval guarantees substantial protection. Further subdivision of these individuals by age, sex, and time period (table $5 \Downarrow$ ) yields relatively wide confidence intervals.

\section{Effect of possible confounding factors}

Information on several other variables that might affect individual risk was available from the mail surveys and clinic interviews. These variables included alcohol intake, highest educational achievement, body mass index, and dose of ionising radiation from the atomic bombs. However, the estimates of smoking related risk scarcely changed after adjusting for any of these possible confounding factors. (table $6 \Downarrow$ and extra table 3 on bmj.com).

\section{Discussion}

Among this Japanese cohort, those who were born in 1920-45, and who started to smoke before age 20 and continued smoking, mortality from all causes combined was more than doubled compared with those who had never smoked, and their reduction in life expectancy was about one decade. However, much of the increase in risk was avoided by giving up smoking, and those who managed to stop by age 35 avoided nearly all of the risk in those who continued to smoke. The confidence intervals for the results in the present study are comparable with the finding in a much larger prospective study in the UK, which finds that stopping smoking by age 30 avoids about $97 \%$ of the increase in risk in continuing smokers ${ }^{34}$ and that, although substantial hazard remains for some decades among those who stop at age 40 , it is only about one tenth of the excess hazard in those who continue smoking. ${ }^{43}$

Among the smokers in this study, the average number of cigarettes smoked per day increased progressively with decade of birth for cohorts born from the end of the 19th century up until the second world war, while the mean age at starting to smoke decreased progressively (fig $1 \Downarrow$ ). Only among those born since 1920 did the number of cigarettes per day and the mean age at starting to smoke approach those in the United States ${ }^{5}$ and Britain. ${ }^{4}$ For example, in the British Doctors' Study, the median age at starting to smoke for continuing smokers who were born during 1900-1930 was 18 years. ${ }^{4}$

In the British Doctors' Study, which was initiated in 1951 with follow-up on six successive occasions, ${ }^{4}$ the death rate ratio for continuing smokers compared with never smokers increased with increasing duration of follow-up. In the present study the average length of follow-up was 23 years, which is considerably longer than in the other major Japanese cohort studies of smoking, where the average length of follow-up is around 10 years. Also, other Japanese studies had only baseline smoking information, while in the present study, smoking status was ascertained more than once for many individuals, as in the British Doctors' Study. Those who had given up smoking by the time they were re-surveyed could therefore be reclassified as former smokers, rather than remaining classified as current smokers. These differences may partly explain why the risks of smoking appear to be greater in this study than in previous Japanese studies. ${ }^{217}$ Even in the present study, however, smoking information has been gathered infrequently. The most recent survey information available for analysis dates from 1992 and individuals who have given up smoking after their latest survey will be classified as current smokers right up until the end of the study. As a result, the true risks of continuing to smoke are probably underestimated in the present study.

The Six Prefecture Study, which was the first major cohort study of the effects of smoking in Japan, included only those born in the period 1900-26. It found increased mortality in current smokers compared with never smokers, but the increases were smaller than in the present study. ${ }^{18}$ More recent Japanese cohorts have included fewer individuals born before 1920 and more 
born after 1930 than the Six Prefecture Study. They found larger increases in mortality for current smokers compared with never smokers than the Six Prefecture Study, ${ }^{17}{ }^{19-22}$ and more consistent with the results of the present study. However previous Japanese studies have not analysed their data by successive decades of birth. If such an analysis had been done, the results could have been similar to those observed in the present study, with larger increases in mortality for current smokers versus never smokers, and also larger reductions in life expectancy for smokers born in more recent decades than for smokers born earlier. Such an effect of birth cohort was also seen in the British Doctors' Study, where the reductions in life expectancy among current smokers compared with never smokers increased progressively for those born before 1900 and to those born during 1900-09, 1910-19, and 1920-29. ${ }^{4}$ In the Six Prefecture Study both male and female smokers who started to smoke at age $<20$ years had slightly higher death rate ratios than smokers who did not start until they were older. ${ }^{19}$ In that early cohort the differences were not significant statistically, but in more recent Japanese studies clearer evidence of an increased risk among those who started smoking at younger ages has been seen, ${ }^{23-28}$ in line with, for example, US studies that found higher all cause mortality in those starting to smoke at younger ages.$^{29}$ However, no previous Japanese study has looked directly at the effect of age at starting to smoke in people born in more recent decades.

During the first half of the 20th century, tobacco consumption was lower in Japan than in the US and many European countries. ${ }^{130}$ From the early 1950 s, tobacco consumption in Japan increased steeply until mid-1970, and since then it has been among the highest in the world. ${ }^{30}$ Each year, the Japan Tobacco Company publishes estimates of the prevalence of smoking for men and women by decade of age from age $20 .^{31}$ Their data suggest that, in $2009,40 \%$ of men and $16 \%$ of women aged 20-29 were smokers, as were $47 \%$ of men and $17 \%$ of women aged 30-39. Smoking before age 20 is illegal in Japan (and has been since 1900), but estimates of its prevalence in school students are available from surveys by the Ministry of Health, Labour and Welfare. The most recent data are for 2004 , at which time $42 \%$ of boys and $27 \%$ of girls in their final year of school (aged 17-18) admitted having tried smoking at least once, while $13 \%$ of boys and $4 \%$ of girls smoked every day, and a further $8 \%$ of boys and $5 \%$ of girls had smoked at least once in the previous month. ${ }^{32}$

The future health risks to young Japanese smokers such as these will be substantial unless they manage to stop. ${ }^{33}$ Although many reports of the risks of smoking among the Japanese have suggested lower risks than studies carried out in Western populations, it is likely that this is due mainly to the inclusion of a large number of individuals who were born in the first quarter of the 20th century and started smoking at later ages and at lower intensities than do Japanese people born more recently. This paper has presented data from Japan, but its relevance is worldwide, as there are many countries where the epidemic of smoking related diseases is not yet sufficiently mature — especially among women — for the full risks of smoking to be apparent.

Our main thanks to the thousands of people who took part in this study, and to the study staff who interviewed them and managed the data in Japan. We also thank help Jill Boreham at the Clinical Trial Service Unit (CTSU), Oxford, for help in preparing this report and Roy Shore at the Radiation Effects Research Foundation (RERF), Hiroshima, for support and encouragement.

Contributors: This study was designed by RS, PMcG, EJG, and SCD, with input from KO and RP. The analysis file used in the study was prepared from master files held at the Radiation Effects Research Foundation (RERF) by EJG and RS. PMcG, RS, EJG, and SCD had access to the analysis file and take responsibility for the accuracy of the analysis. The manuscript was drafted by SCD, PMcG, RS, and EJG with input from the other authors. SCD, RS, EJG, and PMcG are the guarantors for the study.

Funding: RS, EJG, and KO are supported by RERF, Hiroshima and Nagasaki, Japan, a private, non-profit foundation funded by the Japanese Ministry of Health, Labour, and Welfare (MHLW) and the US Department of Energy (DOE), partly through DOE award DE-HS0000031 to the National Academy of Sciences which provides support for EJG. This publication was supported by RERF Research Protocol RP 3-08 and by the MHLW International Exchange Program Fund. The views of the authors do not necessarily reflect those of the two governments. PMcG, RP, and SCD are supported by the core funding to CTSU from Cancer Research UK, British Heart Foundation, and Medical Research Council.

The funding organisations had no role in study design, data collection, analysis, interpretation, writing the report or the decision to submit it for publication.

Competing interests: All authors have completed the ICMJE uniform disclosure form at www.icmje.org/coi_disclosure.pdf (available on request from the corresponding author) and declare: no financial relationships with any organisations that might have an interest in the submitted work in the previous three years, and no other relationships or activities that could appear to have influenced the submitted work.

Data sharing: No additional data are available.

Tobacco Free Japan. Tobacco Free Japan: recommendation for tobacco control policy in Japan [in Japanese]. 2005. www.tobaccofree.jp/J/Full.html.

2 Ozasa K, Katanoda K, Tamakoshi A, Sato H, Tajima K, Suzuki T, et al. Reduced life expectancy due to smoking in large-scale cohort studies in Japan. J Epidemiol 2008;18:111-8.

3 Murakami Y, Ueshima H, Okamura T, Kadowaki T, Hozawa A, Kita Y, et al. Life expectancy among Japanese of different smoking status in Japan: NIPPON DATA80. J Epidemiol 2007; $17: 31-7$.

4 Doll R, Peto R, Boreham J, Sutherland I. Mortality in relation to smoking: 50 years observation on male British doctors. BMJ 2004;328:1519-28.

5 Mamun AA, Peeters A, Barendregt J, Willekens F, Nusselder W, Bonneux L, et al. Smoking decreases the duration of life lived with and without cardiovascular disease: a life course analysis of the Framingham Heart Study. Eur Heart J 2004:25:409-15.

6 Akiba S. Analysis of cancer risk related to longitudinal information on smoking habits. Environ Health Perspect 1994;102:15-9.

7 Yamada M, Wong FL, Fujiwara S, Tatsukawa Y, Suzuki G. Smoking and alcohol habits as risk factors for benign digestive diseases in a Japanese population: the Radiation Effects Research Foundation Adult Health Study. Digestion 2005;71:231-7.

8 Furukawa K, Preston DL, Lonn S, Funamoto S, Yonehara S, Matsuo T, et al. Radiation and smoking effects on lung cancer incidence among atomic bomb survivors. Radiat Res 2010;174:72-82.

9 Sauvaget C, Lagarde F, Nagano J, Soda M, Koyama K, Kodama K. Lifestyle factors, radiation and gastric cancer in atomic-bomb survivors (Japan). Cancer Causes Control 2005;16:773-80.

10 Ozasa K, Shimizu Y, Suyama A, Kasagi F, Soda M, Grant EJ, et al. Studies of the mortality of atomic bomb survivors, report 14, 1950-2003: an overview of cancer and noncancer diseases. Radiat Res 2012;177:229-43.

11 Grant EJ, Ozasa K, Preston DL, Suyama A, Shimizu Y, Sakata R, et al. Effects of radiation and lifestyle factors on risks of urothelial carcinoma in the life span study of atomic bomb survivors. Radiat Res 2012;178:86-98.

12 Sagan LA, Ishimaru T, Onishi S, Johnson KG, Kato H, Wakabayashi T. Epidemiologic survey, Adult Health Study sample, Hiroshima and Nagasaki. Atomic Bomb Casualty Commisssion, 1963. (Research protocol 26-63.)

13 Kato $\mathrm{H}$, Yano K, Johnson KG. Study of cardiovascular disease, Hiroshima and Nagasaki: mortality related to family history and habits. Atomic Bomb Casualty Commission, 1965 (Research protocol 9-65.)

14 Wakabayashi T. Mail questionnaire survey for epidemiologic data on females in the JNIH-ABCC Life Span Study sample. Atomic Bomb Casualty Commission, 1969. (Research protocol 11-69.)

15 Chief of Epidemiology and Statistics. Mail questionnaire survey for epidemiologic data on the Life Span Study extended sample, 1978. Radiation Effects Research Foundation, 1978. (Research protocol 14-78.)

16 Akiba S, Shibata Y, Kasagi F, Shimaoka K, Land CE, Yamada M, et al. Mail survey on epidemiologic factors in the Extended Life Span Study sample, 1991. Radiation Effects Research Foundation, 1991. (Research protocol 4-91.)

17 Murakami Y, Miura K, Okamura T, Ueshima H, EPOCH-JAPAN Research Group. Population attributable numbers and fractions of deaths due to smoking: a pooled analysis of 180,000 Japanese. Prev Med 2011;52:60-5.

18 Hirayama T. Life-style and mortality: a large-scale census-based cohort study in Japan Karger, 1990.

19 Uno F, Ishikawa S, Nakamura Y, Gotoh T, Nago N, Kayaba K, et al. Smoking and risk of all-cause mortality: the Jichi Medical School (JMS) Cohort Study. J Epidemiol 2005;15:173-9. 


\section{What is already known on this topic}

In a prospective study of British doctors, those who smoked cigarettes throughout their adult life died about 10 years earlier than lifelong non-smokers, while in the US Framingham Heart Study life expectancy in continuing smokers was also nearly 10 years lower than in lifelong non-smokers

In contrast, analyses of data from four large prospective studies in Japan had suggested that smoking reduced life expectancy by only about four years

\section{What this study adds}

Japanese smokers born before about 1920 smoked fewer cigarettes per day on average than those born more recently, and many Japanese smokers born before 1945 did not start smoking until well into adult life

Japanese smokers born since 1920 and who started to smoke early in adult life had smoking habits similar to those of smokers in the British Doctors' Study and the Framingham Heart Study and, as in those studies, continuing smokers lost about 10 years of life compared with lifelong non-smokers

Previous Japanese studies have underestimated the effect of smoking for modern Japanese adults because they included large numbers of people born in the first few decades of the 20th century who had started smoking at later ages and smoked at lower intensities than is typical of Japanese smokers born more recently

The findings of this paper are of relevance to all populations where the epidemic of smoking-related diseases is not yet sufficiently mature for the full risks of smoking to be apparent

20 Hozawa A, Ohkubo T, Yamaguchi J, Ugajin T, Koizumi Y, Nishino Y, et al. Cigarette smoking and mortality in Japan: the Miyagi Cohort Study. J Epidemiol 2004;14(suppl 1):S12-7.

21 Katanoda K, Marugame T, Saika K, Satoh H, Tajima K, Suzuki T, et al. Population attributable fraction of mortality associated with tobacco smoking in Japan: a pooled analysis of three large-scale cohort studies. J Epidemiol 2008;18:251-64.

22 Pham TM, Fujino Y, Ide R, Shirane K, Tokui N, Kubo T, et al. Mortality attributable to cigarette smoking in a cohort study in Japan. Eur J Epidemiol 2007;22:599-605.

23 Hara M, Inoue M, Shimazu T, Yamamoto S, Tsugane S, for the Japan Public Health Center-based Prospective Study Group. The Association between cancer risk and age at onset of smoking in Japanese. J Epidemiol 2010;20:128-35.

24 Ozasa K. Smoking and mortality in the Japan Collaborative Study for Evaluation of Cance (JACC). Asian Pacific J Cancer Prev 2007;8(JACC suppl):s89-96.

25 Ando M, Wakai K, Seki N, Tamakoshi A, Suzuki K, Ito Y, et al. Attributable and absolute risk of lung cancer death by smoking status: findings from the Japan Collaborative Cohort Study. Int J Cancer 2003;105:249-54.

26 Inoue M, for the JPHC Study Group. Impact of tobacco smoking on subsequent cancer risk among middle-aged Japanese men and women: data from a large-scale population-based cohort study in Japan—-the JPHC study. Prev Med 2004:38:516-22.

27 Lin Y, Tamakoshi A, Kawamura T, Inaba Y, Kikuchi S, Motohashi Y, et al. Japan Collaborative Cohort: a prospective cohort study of cigarette smoking and pancreatic cancer in Japan. Cancer Causes Control 2002;13:249-54.

28 Sakata K, Hoshiyama Y, Morioka S, Hashimoto T, Takeshita T, Tamakoshi A, et al. Smoking, alcohol drinking and esophageal cancer: findings from the JACC Study. $J$ Epidemiol 2005;15(suppl 2):S212-9.
29 Kenfield SA, Stampfer MJ, Rosner BA, Colditz GA. Smoking and smoking cessation in relation to mortality in women. JAMA 2008;299:2037-47.

30 Forey B, Hamling J, Hamling J, Lee P, eds: International smoking statistics. A collection of historical data from 30 economically developed countries. P N Lee Statistics \& Computing, 2006. (www.pnlee.co.uk/iss.htm)

31 Japan Health Promotion \& Fitness Foundation. Japan Tobacco Incorporated Survey. 2008. www.health-net.or.jp/tobacco/product/pd090000.html.

32 Japan Health Promotion \& Fitness Foundation. The national survey of underage smoking and drinking. 2008. www.health-net.or.jp/tobacco/product/pd110000.html.

33 IARC. The hazards of smoking and the benefits of stopping: cancer mortality and overal mortality. In: IARC handbooks of cancer prevention, tobacco control. Vol 11. Reversal of risk after quitting smoking . IARC, 2007.

34 Pirie K, Peto R, Reeves GK, Green J, Beral V for the Million Women Study Collaborators. The 21 st century hazards of smoking and benefits of stopping: a prospective study of one million women in the UK. Lancet (forthcoming).

\section{Accepted: 17 October 2012}

\section{Cite this as: BMJ 2012;345:e7093}

This is an open-access article distributed under the terms of the Creative Commons Attribution Non-commercial License, which permits use, distribution, and reproduction in any medium, provided the original work is properly cited, the use is non commercial and is otherwise in compliance with the license. See: http://creativecommons.org/licenses/bync/2.0/ and http://creativecommons.org/licenses/by-nc/2.0/legalcode. 


\section{Tables}

Table 1| Mail surveys and clinic interviews during which smoking information was observed for members of the Life Span Study cohort

\begin{tabular}{|c|c|c|c|}
\hline Year of survey (reference for survey protocol) & Target population & No of respondents & Response rate (\%) \\
\hline \multicolumn{4}{|l|}{ Interview based clinic surveys } \\
\hline $1963-64$ (Sagan et al $1963^{12}$ ) & AHS cohort & 9315 & \multirow[t]{3}{*}{$85-90^{*}$} \\
\hline 1964-68 (Sagan et al $1963^{12}$ ) & AHS cohort & 12776 & \\
\hline $1968-70$ (Sagan et al $1963^{12}$ ) & AHS cohort & 11203 & \\
\hline \multicolumn{4}{|l|}{ Mail surveys } \\
\hline $1965\left(\right.$ Kato et al $\left.1965^{13}\right)$ & LSS cohort, men aged $40-69$ years & 12321 & 94 \\
\hline 1969-71 (Wakabayashi 1969'14) & LSS cohort, women, excluding AHS cohort & 20831 & 53 \\
\hline 1978-81 (Chief of Epidemiology and Statistics $1978^{15}$ ) & LSS cohort, excluding NIC subjects† & 40347 & 72 \\
\hline 1991-92 (Akiba et al1991 ${ }^{16}$ ) & LSS cohort, excluding AHS cohort and NIC subjects $†$ & 33220 & 76 \\
\hline
\end{tabular}

AHS cohort=Adult Health Study cohort (a subset of the Life Span Study cohort). LSS= Life Span Study.

*Range of participation rates in AHS health examination cycles.

†Subjects who were not in city at the time of the bombings. 
Table 2/ Study population (of survey respondents who gave information on smoking status) by survey period, sex, and smoking status. Values are numbers of respondents (with row percentages)

\begin{tabular}{|c|c|c|c|c|}
\hline \multirow[b]{2}{*}{ Survey period } & \multicolumn{3}{|c|}{ Smoking status } & \multirow[b]{2}{*}{ Total } \\
\hline & Never & Current & Former & \\
\hline \multicolumn{5}{|c|}{ No of responders in each survey period } \\
\hline \multicolumn{5}{|l|}{ Men: } \\
\hline $1963-71^{*}$ & $1835(13)$ & $10218(74)$ & $1744(13)$ & $13797(100)$ \\
\hline $1978-81$ & $2196(15)$ & $9088(63)$ & $3139(22)$ & $14423(100)$ \\
\hline $1991-92$ & $1879(17)$ & $5781(52)$ & 3427 (31) & $11087(100)$ \\
\hline \multicolumn{5}{|l|}{ Women: } \\
\hline $1963-71^{*}$ & $20957(85)$ & $3274(13)$ & $519(2)$ & $24750(100)$ \\
\hline $1978-81$ & $19555(84)$ & $2536(11)$ & $1077(5)$ & $23168(100)$ \\
\hline $1991-92$ & $16483(84)$ & $1579(8)$ & $1457(8)$ & $19519(100)$ \\
\hline \multicolumn{5}{|c|}{ Cumulative number of responders (all periods) $\dagger$} \\
\hline \multicolumn{5}{|l|}{ Men: } \\
\hline Total & $3873(14)$ & $16318(60)$ & $7120(26)$ & $27311(100)$ \\
\hline Started smoking at age $<20$ years & - & 4363 & 1479 & 5842 \\
\hline \multicolumn{5}{|l|}{ Women: } \\
\hline Total & $33736(83)$ & $4494(11)$ & $2432(6)$ & $40662(100)$ \\
\hline Started smoking at age $<20$ years & - & 248 & 109 & 357 \\
\hline
\end{tabular}

*Surveys were by mail except for 5531 men and 8549 women interviewed in clinics during the first survey period.

†People taking part in more than one survey period are counted only once and are classified by their most recent known smoking status. A further 2738 people were surveyed but did not provide information on smoking status. 
Table 3| Mortality from all causes by sex and year of birth among never smokers and current smokers

\begin{tabular}{|c|c|c|c|c|c|}
\hline \multirow[b]{2}{*}{ Year of birth } & \multicolumn{2}{|c|}{ Never smokers } & \multicolumn{2}{|c|}{ Current smokers } & \multirow[b]{2}{*}{ Rate ratio $(95 \% \mathrm{Cl})$ current $v$ never smokers } \\
\hline & No of deaths & Death rate* & No of deaths & Death rate* & \\
\hline \multicolumn{6}{|l|}{ Men: } \\
\hline$<1890$ & 40 & 43.0 & 72 & 53.4 & 1.24 (0.84 to 1.83$)$ \\
\hline $1890-99$ & 455 & 27.5 & 1529 & 38.2 & $1.39(1.25$ to 1.54$)$ \\
\hline $1900-09$ & 696 & 23.4 & 3122 & 34.9 & 1.49 (1.37 to 1.62$)$ \\
\hline $1910-19$ & 401 & 17.6 & 2300 & 27.3 & 1.55 (1.39 to 1.72$)$ \\
\hline $1920-29$ & 160 & 14.1 & 1384 & 25.7 & $1.82(1.55$ to 2.15$)$ \\
\hline \multirow[t]{2}{*}{$1930-45$} & 244 & 11.3 & 1705 & 21.7 & $1.92(1.68$ to 2.20$)$ \\
\hline & & & & & $P_{\text {trend }}=0.00001$ \\
\hline \multicolumn{6}{|l|}{ Women: } \\
\hline$<1890$ & 418 & 35.8 & 82 & 47.2 & $1.32(1.04$ to 1.67$)$ \\
\hline 1890-99 & 1977 & 29.0 & 364 & 40.0 & $1.38(1.23$ to 1.54$)$ \\
\hline $1900-09$ & 4421 & 23.6 & 757 & 33.3 & 1.41 (1.31 to 1.53$)$ \\
\hline $1910-19$ & 3779 & 14.9 & 744 & 25.2 & 1.69 (1.56 to 1.83$)$ \\
\hline $1920-29$ & 2608 & 11.7 & 514 & 21.3 & 1.82 (1.66 to 2.00$)$ \\
\hline \multirow[t]{2}{*}{$1930-45$} & 1147 & 9.6 & 217 & 17.2 & 1.79 (1.55 to 2.07$)$ \\
\hline & & & & & $P_{\text {trend }}<0.00001$ \\
\hline
\end{tabular}

${ }^{*}$ Rate per 1000 person years, standardised for age. 
Table 4| No of deaths from all causes and death rate ratios among current smokers compared with never smokers by sex, year of birth, and age at starting smoking

\begin{tabular}{|c|c|c|c|c|c|c|c|c|}
\hline & \multicolumn{4}{|c|}{ Men } & \multicolumn{4}{|c|}{ Women } \\
\hline & \multicolumn{2}{|c|}{ Born before 1920} & \multicolumn{2}{|c|}{ Born 1920-45 } & \multicolumn{2}{|c|}{ Born before 1920} & \multicolumn{2}{|c|}{ Born 1920-45 } \\
\hline & $\begin{array}{l}\text { No of } \\
\text { deaths }\end{array}$ & $\begin{array}{l}\text { Rate ratio }(95 \% \mathrm{Cl}) \\
v \text { never smokers }\end{array}$ & $\begin{array}{l}\text { No of } \\
\text { deaths }\end{array}$ & $\begin{array}{c}\text { Rate ratio }(95 \% \mathrm{Cl}) \\
v \text { never smokers }\end{array}$ & $\begin{array}{l}\text { No of } \\
\text { deaths }\end{array}$ & $\begin{array}{c}\text { Rate ratio }(95 \% \mathrm{Cl}) \\
v \text { never smokers }\end{array}$ & $\begin{array}{l}\text { No of } \\
\text { deaths }\end{array}$ & $\begin{array}{l}\text { Rate ratio }(95 \% \mathrm{Cl}) \\
v \text { never smokers }\end{array}$ \\
\hline \multicolumn{9}{|c|}{ Current smokers } \\
\hline \multicolumn{9}{|l|}{$\begin{array}{l}\text { Age started } \\
\text { smoking } \\
\text { (years): }\end{array}$} \\
\hline$<20$ & 1272 & 1.66 (1.54 to 1.79$)$ & 1121 & 2.21 (1.97 to 2.48$)$ & 68 & 1.54 (1.21 to 1.95$)$ & 51 & 2.61 (1.98 to 3.44$)$ \\
\hline $20-29$ & 4862 & $1.42(1.34$ to 1.51$)$ & 1674 & 1.71 (1.53 to 1.91$)$ & 369 & $1.53(1.38$ to 1.70$)$ & 311 & 2.01 (1.79 to 2.25$)$ \\
\hline$\geq 30$ & 657 & 1.17 (1.07 to 1.29$)$ & 40 & 1.48 (1.07 to 2.05$)$ & 677 & 1.26 (1.16 to 1.36$)$ & 200 & 1.40 (1.22 to 1.62$)$ \\
\hline $\begin{array}{l}\mathrm{P} \text { value for } \\
\text { trend }\end{array}$ & & $<0.00001$ & & $<0.00001$ & & 0.001 & & $<0.00001$ \\
\hline $\begin{array}{l}\text { Unknown age } \\
\text { started } \\
\text { smoking }\end{array}$ & 232 & 2.85 (2.48 to 3.28 ) & 254 & 2.04 (1.74 to 2.39 ) & 833 & 1.78 (1.65 to 1.91$)$ & 169 & 1.94 (1.67 to 2.27 ) \\
\hline All ages & 7023 & $1.46(1.38$ to 1.54$)$ & 3089 & 1.89 (1.70 to 2.10$)$ & 1947 & 1.51 (1.43 to 1.58$)$ & 731 & 1.81 (1.67 to 1.96$)$ \\
\hline \multicolumn{9}{|c|}{ Never smokers } \\
\hline All ages & 1592 & - & 404 & - & 10595 & - & 3755 & - \\
\hline
\end{tabular}


Table 5 | No of deaths from all causes and death rate ratios among former smokers by sex, year of birth, and age at quitting smoking

\begin{tabular}{|c|c|c|c|c|c|c|c|c|}
\hline & \multicolumn{3}{|c|}{ Men } & \multicolumn{3}{|c|}{ Women } & \multicolumn{2}{|c|}{ Men and women } \\
\hline & $\begin{array}{c}\text { Mean age } \\
\text { when quit } \\
\text { (years) }\end{array}$ & $\begin{array}{l}\text { No of } \\
\text { deaths }\end{array}$ & $\begin{array}{c}\text { Rate ratio }(95 \% \mathrm{Cl}) v \\
\text { never smokers }{ }^{*}\end{array}$ & $\begin{array}{c}\text { Mean age } \\
\text { when quit } \\
\text { (years) }\end{array}$ & $\begin{array}{l}\text { No of } \\
\text { deaths }\end{array}$ & $\begin{array}{c}\text { Rate ratio }(95 \% \mathrm{Cl}) v \\
\text { never smokers* }\end{array}$ & $\begin{array}{l}\text { No of } \\
\text { deaths }\end{array}$ & $\begin{array}{c}\text { Rate ratio }(95 \% \mathrm{Cl}) v \\
\text { never smokers }\end{array}$ \\
\hline Born before 1920 & & & & & & & & \\
\hline
\end{tabular}

Former smokers:

Age quit smoking

(years):

\begin{tabular}{lccccccccc}
\hline$<25$ & 22 & 32 & $1.19(0.84$ to 1.68$)$ & 21 & 3 & $0.89(0.29$ to 2.75$)$ & 35 & $1.13(0.81$ to 1.58$)$ \\
\hline $25-34$ & 30 & 125 & $1.13(0.94$ to 1.36$)$ & 30 & 30 & $1.16(0.81$ to 1.65$)$ & 155 & $1.12(0.95$ to 1.31$)$ \\
\hline $35-44$ & 40 & 253 & $1.09(0.95$ to 1.24$)$ & 40 & 56 & $1.04(0.80$ to 1.36$)$ & 309 & $1.06(0.94$ to 1.19$)$ \\
\hline $45-54$ & 50 & 540 & $1.11(1.00$ to 1.22$)$ & 50 & 123 & $0.93(0.78$ to 1.11$)$ & 663 & $1.05(0.97$ to 1.15$)$ \\
\hline $55-64$ & 59 & 732 & $1.23(1.12$ to 1.34$)$ & 60 & 200 & $1.22(1.06$ to 1.40$)$ & 932 & $1.21(1.12$ to 1.30$)$ \\
\hline$\geq 65$ & 71 & 700 & $1.45(1.33$ to 1.59$)$ & 72 & 250 & $1.31(1.15$ to 1.48$)$ & 950 & $1.39(1.29$ to 1.49$)$ \\
\hline P value for trend & & & 0.000003 & & & 220 & $1.45(1.27$ to 1.66$)$ & 381 & $1.47(1.32$ to 1.62$)$ \\
\hline Unknown age & & 161 & $1.51(1.28$ to 1.78$)$ & & & 1947 & $1.50(1.43$ to 1.58$)$ & 8970 & $1.47(1.41$ to 1.52$)$ \\
\hline Current smokers & - & 7023 & $1.45(1.37$ to 1.53$)$ & - & - & 10595 & - & &
\end{tabular}

Born 1920-45

Former smokers:

Age quit smoking

(years):

\begin{tabular}{|c|c|c|c|c|c|c|c|c|}
\hline$<25$ & 22 & 20 & 0.91 (0.58 to 1.42$)$ & 22 & 5 & 1.54 (0.64 to 3.70$)$ & 25 & $0.98(0.66$ to 1.46$)$ \\
\hline $25-34$ & 30 & 85 & $0.83(0.66$ to 1.05$)$ & 29 & 24 & $1.21(0.81$ to 1.81$)$ & 109 & $0.89(0.73$ to 1.09$)$ \\
\hline $35-44$ & 39 & 200 & 1.21 (1.02 to 1.44$)$ & 39 & 46 & 1.27 (0.95 to 1.70$)$ & 246 & $1.22(1.06$ to 1.40$)$ \\
\hline $45-54$ & 49 & 273 & 1.43 (1.23 to 1.68$)$ & 49 & 74 & 1.59 (1.26 to 2.00$)$ & 347 & $1.46(1.29$ to 1.65$)$ \\
\hline $55-64$ & 58 & 206 & 1.73 (1.45 to 2.06$)$ & 59 & 61 & 1.49 (1.15 to 1.92$)$ & 267 & 1.65 (1.44 to 1.90$)$ \\
\hline$\geq 65$ & 67 & 29 & 1.72 (1.16 to 2.57 ) & 67 & 14 & 1.94 (1.15 to 3.29$)$ & 43 & 1.78 (1.30 to 2.45$)$ \\
\hline$P$ value for trend & & & $<0.00001$ & & & 0.09 & & $<0.00001$ \\
\hline Unknown age & & 90 & 2.14 (1.70 to 2.69$)$ & & 74 & 1.55 (1.23 to 1.95$)$ & 164 & 1.82 (1.56 to 2.14$)$ \\
\hline Current smokers & - & 3089 & 1.89 (1.70 to 2.09 ) & - & 731 & 1.81 (1.67 to 1.96$)$ & 3820 & 1.84 (1.74 to 1.96$)$ \\
\hline Never smokers & - & 404 & - & - & 3755 & - & 4159 & - \\
\hline
\end{tabular}

*Death rate ratios stratified for age, calendar period, and (when men and women combined) sex. 
Table 6 | Association between most recent smoking status and mortality stratified for possible confounding factors, as well as age and calendar year. Values are death rate ratios $(95 \%$ confidence intervals)

\begin{tabular}{|c|c|c|c|c|c|c|}
\hline \multirow[b]{2}{*}{ Additional stratification } & \multicolumn{3}{|c|}{ Men } & \multicolumn{3}{|c|}{ Women } \\
\hline & Never smokers* & Current smokers & Former smokers & Never smokers* & Current smokers & Former smokers \\
\hline \multicolumn{7}{|l|}{ All individuals } \\
\hline None† & 1.00 & 1.55 (1.48 to 1.63$)$ & 1.26 (1.19 to 1.33$)$ & 1.00 & 1.58 (1.51 to 1.64$)$ & $1.28(1.21$ to 1.36$)$ \\
\hline Alchohol intake (g/week) & 1.00 & $1.52(1.44$ to 1.59$)$ & 1.25 (1.18 to 1.32$)$ & 1.00 & $1.58(1.52$ to 1.65$)$ & $1.29(1.22$ to 1.37$)$ \\
\hline Body mass index $\left(\mathrm{kg} / \mathrm{m}^{2}\right)$ & 1.00 & 1.55 (1.48 to 1.63$)$ & 1.26 (1.19 to 1.33$)$ & 1.00 & $1.56(1.50$ to 1.63$)$ & $1.28(1.21$ to 1.36$)$ \\
\hline Highest education status & 1.00 & 1.55 (1.48 to 1.63$)$ & $1.27(1.20$ to 1.34$)$ & 1.00 & 1.54 (1.48 to 1.60$)$ & $1.27(1.20$ to 1.35$)$ \\
\hline Radiation dose (mGy to lung) & 1.00 & 1.57 (1.49 to 1.65$)$ & 1.26 (1.19 to 1.33$)$ & 1.00 & $1.58(1.51$ to 1.64$)$ & $1.27(1.20$ to 1.35$)$ \\
\hline \multicolumn{7}{|c|}{ Individuals who started to smoke at age $<20$ years only } \\
\hline None† & 1.00 & $1.84(1.73$ to 1.96$)$ & $1.34(1.22$ to 1.47$)$ & 1.00 & 1.87 (1.56 to 2.25$)$ & $1.65(1.24$ to 2.19$)$ \\
\hline Alchohol intake (g/week) & 1.00 & 1.81 (1.70 to 1.93$)$ & $1.34(1.22$ to 1.47$)$ & 1.00 & $1.92(1.60$ to 2.31$)$ & $1.69(1.27$ to 2.25$)$ \\
\hline Body mass index $\left(\mathrm{kg} / \mathrm{m}^{2}\right)$ & 1.00 & $1.86(1.75$ to 1.98$)$ & 1.35 (1.23 to 1.48$)$ & 1.00 & 1.85 (1.55 to 2.22$)$ & $1.64(1.23$ to 2.18$)$ \\
\hline Highest education status & 1.00 & $1.82(1.71$ to 1.94$)$ & $1.34(1.22$ to 1.47$)$ & 1.00 & 1.81 (1.51 to 2.22$)$ & $1.58(1.19$ to 2.11$)$ \\
\hline Radiation dose (mGy to lung) & 1.00 & 1.85 (1.73 to 1.97$)$ & 1.35 (1.23 to 1.48$)$ & 1.00 & 1.89 (1.58 to 2.27 ) & 1.60 (1.20 to 2.14$)$ \\
\hline
\end{tabular}

${ }^{\star}$ Reference category.

†Stratification for age and calendar year only. 


\section{Figures}
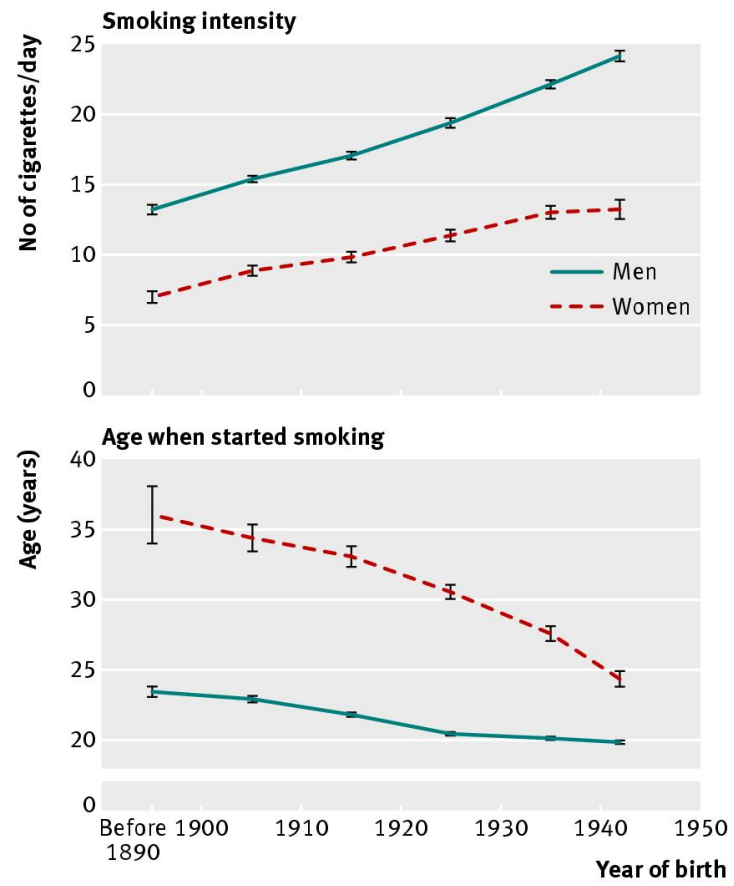

Fig 1 Characteristics of smokers by sex and year of birth. Top: mean number of cigarettes smoked per day by current smokers (calculated as average of all reported). Bottom: mean age at which current smokers started to smoke. (Error bars show $95 \%$ confidence intervals)
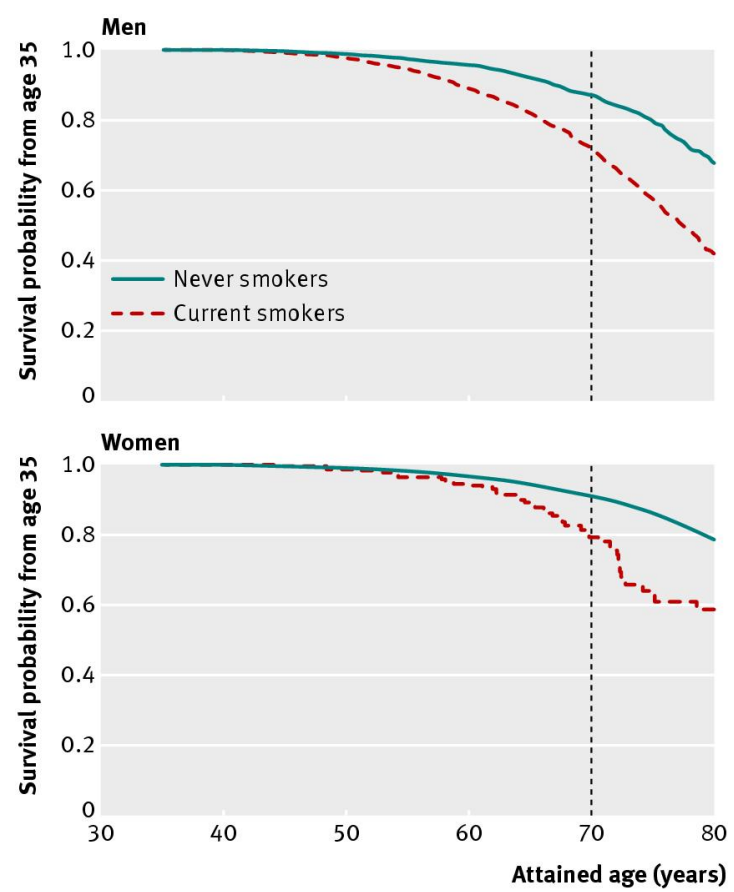

Fig 2 Survival from age 35 years for Japanese men and women born between 1920 and 1945 who were never smokers or who started to smoke before age 20 years and continued smoking (mean smoking intensity among smokers of 23 cigarettes/day for men and 17 cigarettes/day for women). (Additional survival curves are given in extra figs 2 and 3 in supplementary material on bmj.com) 